\title{
Dynamics-Based Stranded-Crowd Model for Evacuation in Building Bottlenecks
}

\author{
Lidi Huang, ${ }^{1,2}$ Deming Liu, ${ }^{1}$ and Yongyi Zhang ${ }^{2}$ \\ ${ }^{1}$ School of Architecture, Harbin Institute of Technology, Harbin, Heilongjiang 150001, China \\ ${ }^{2}$ College of Civil and Architecture Engineering, Northeast Petroleum University, Daqing, Heilongjiang 163318, China \\ Correspondence should be addressed to Lidi Huang; huangld@yeah.net
}

Received 7 December 2012; Revised 5 January 2013; Accepted 15 January 2013

Academic Editor: Sheng-Yong Chen

Copyright (c) 2013 Lidi Huang et al. This is an open access article distributed under the Creative Commons Attribution License, which permits unrestricted use, distribution, and reproduction in any medium, provided the original work is properly cited.

\begin{abstract}
In high-density public buildings, it is difficult to evacuate. So in this paper, we propose a novel quantitative evacuation model to insure people's safety and reduce the risk of crowding. We analyze the mechanism of arch-like clogging phenomena during evacuation and the influencing factors in emergency situations at bottleneck passages; then we design a model based on crowd dynamics and apply the model to a stadium example. The example is used to compare evacuation results of crowd density with different egress widths in stranded zones. The results show this model proposed can guide the safe and dangerous egress widths in performance design and can help evacuation routes to be selected and optimized.
\end{abstract}

\section{Introduction}

One of the most important essential requirements for safety design of a building is safe evacuation of people from buildings in emergency conditions. From the early 20th century, there have been a lot of disasters that occurred during emergency evacuation of crowds. For example, 173 people died in the 1943 stampede incident in the subway station in London, UK; in the 1989 Hillsborough English FA Cup Stampede, 96 people died, and 400 were injured [1]; 20 soccer fans were killed during a stampede at a soccer game which became Africa's worst sports-related disaster in Accra, Ghana, in 2001; 21 children died, and 47 people were injured in a grandstand failure at a school in Xuzhou, China, in 2002, and so forth [2]. So it is very significant to study on safe design of large scale buildings and influence factors during the evacuation process, since these incidents often occurred in high-density crowds buildings.

There have been more than one hundred years for the research on human behavior during the evacuation process. With improvement of computer technology, the research has developed to computer simulation $[3,4]$ from the initial postdisaster investigations. Egress modeling is one of the most important means of egress investigation $[5,6]$. Popular models, such as the social force model [7] and the discrete model [8], the latter including lattice gas model and cellular automata model, are able to successfully simulate some typical phenomena observed in pedestrian dynamics. Software based on the above models, EVACENT4, STEPS, building EXODUS, EXITT, Legion, and so forth, have been applied widely to simulate and evaluate very complex factors influencing people evacuation. Recently, some experimental results have also been presented to validate the models of pedestrian flow and evacuation [9-11].

However, it is very complicated to analyze human behavior in emergency conditions. Furthermore, systematic study on panic behavior and quantitative theories of predicting crowd dynamics are few. Computation for especially determination of people evacuation is so complex that their application is limited. Thus, several authors have devoted their work to the research of simple model and the calculation of evacuation time. Zhang et al. $[12,13]$ proposed an SCM to calculate the number of stranded crowd with different egress widths and modify the evacuation time; Liu et al. [14] developed an evacuation model of crowd streams at a stadium to calculate and analyze the total evacuation time.

Relieving panic and stress of people from building space and construction environment is the duty of architects. However, evacuation design research has not been properly 


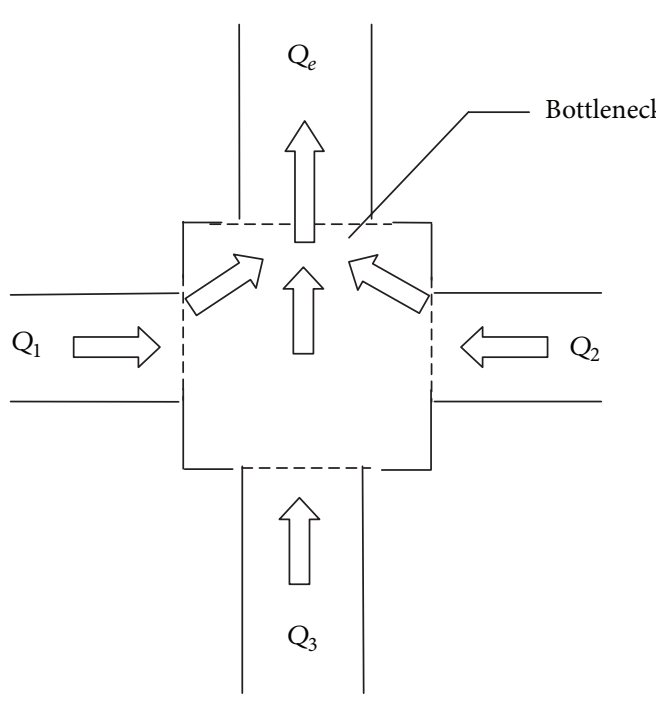

(a)

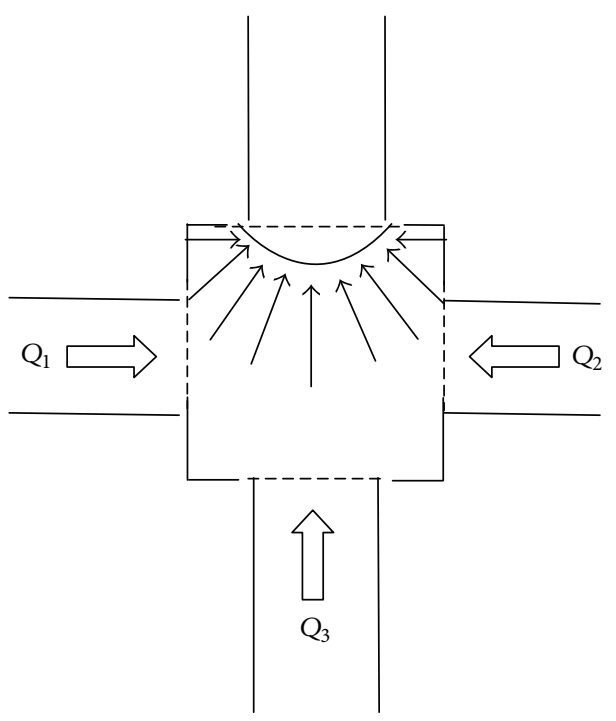

(b)

FIGURE 1: Sketch of typical bottleneck.

established in architectural discipline. Thus, the current study hopes to serve such a need and is inspired by the study of Zhang et al. [12] and Liu et al. [14]. In this paper, a simple continuous-time model based on the dependency of physical parameters (density, velocity, and flow-rate) is set up to discuss the concepts of safe space design in terms of evacuation processes efficiency in high-density crowd situations and panicked behavior. This paper intends to introduce this model and apply the analysis results to architectures, to provide modifications in architectural layouts to optimize evacuation.

A brief description of the organization of this paper is as follows. The main calculation principles in this paper are stated in Section 3. The parameters analysis of Section 3 is described in Section 2. The application is given in Section 4. The results and analysis of the application are considered in Section 5. Finally, a conclusion is drawn to summarize the paper.

\section{Preliminaries}

2.1. Concept. The evacuation route of pedestrians in a stadium can be simply attributed as leaving from spectators' stands to vertical passages, from passages to doors or stairs, and then to safe areas. Traffic nodes among the evacuation routes, such as changed building space, narrowed channels, incompletely opened exits, merging points of several crowd streams (Figure 1(a)), and stairs, are called "Building Bottlenecks," and where potential hazards would break out in the case of high gathering crowd. In an urgent situation, crowd streams from spacious areas rushing here would hinder the positive streams flowing out, increase crowd density, and then form an irregular succession of arch-like blockings at exit bottlenecks (Figure 1(b)), which instantaneously causes a cease in evacuation flow, and when the arches break, pedestrians will suddenly leave just like avalanche bunches $[15,16]$. More seriously, this phenomenon can cause people psychological panic and induce collective human behavior, a crowd stampede, which is one of the most disastrous forms, often leading to fatalities as people are crushed or trampled [17].

2.2. Parameters Analysis. During the last few decades, pedestrians flow and evacuation have attracted researchers' attention. They concluded that egress evacuation capacity is related to egress width, $w$, m, egress stream flow-rate, $f$, persons/(ms), crowd velocity, $v, \mathrm{~m} / \mathrm{s}$, and crowd density, $\rho$, persons $/ \mathrm{m}^{2}$.

Egress stream flow-rate is the number of persons passing through per unit of distance width of evacuation passage or exit per unit of time, person/(ms), crowd velocity is moving distances per unit of time, $\mathrm{m} / \mathrm{s}$, and crowd density is the number of persons per unit area, persons $/ \mathrm{m}^{2}$.

It is essential to understand the main characteristics of their relationship among the above parameters. In the past, researches about these parameters were mainly through two kinds of means: field observation and video record. So far, Predteckenskii and Milinski [18], Fruin [19], Ando et al. [20], Paul [21], Nelson and Maclennan [22], Smith and Petly [23], and $\mathrm{Lu}$ [24] et al., have already accumulated a large amount of observation data, from which typical relationship curves between the crowd density and velocity was summarized by Thompson (Figure 2) [25]. In general, in different environments and with different observation methods, each result of fleeing velocity varies slightly because of all kinds of constraints, but the changing trend of these curves is similar; that is, an increase in crowd streams density makes the distance between people decrease, and makes personnel movement velocity slow; on the contrary, a decrease in the density makes personnel movement velocity increase. 


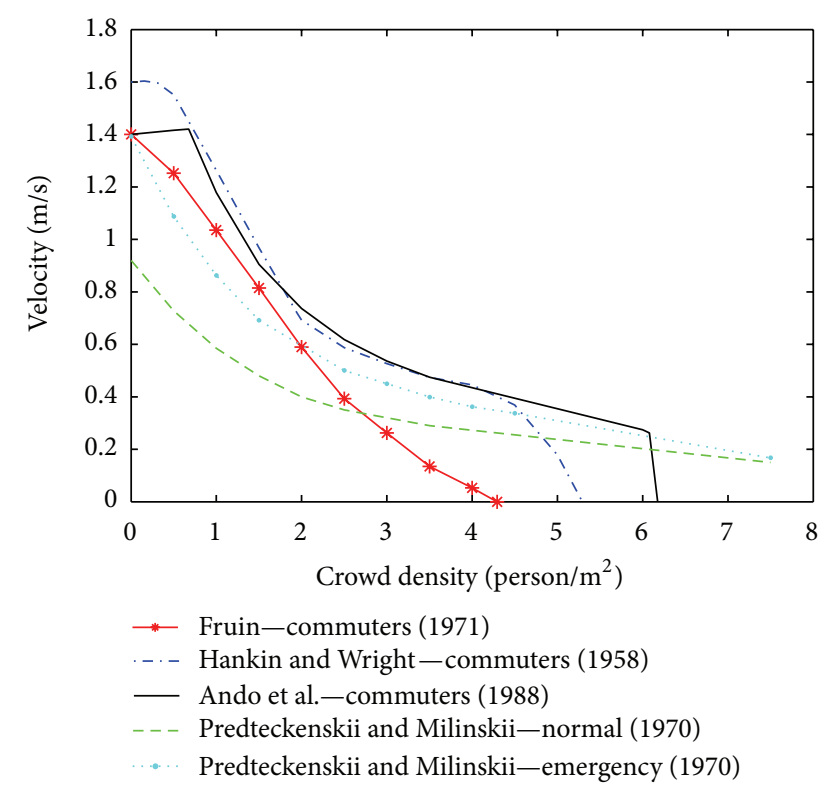

FIGURE 2: The relationship of crowd density and velocity.

Based on influence mechanism of personnel acceleration that is produced by people around in urgency evacuation from buildings, $\mathrm{Lu}$ et al. [24] proposed a velocity dynamics equation under crowding environment, which is a function of density:

$$
\begin{gathered}
v(\rho)=v_{m}(\alpha A+\beta B+\gamma), \\
A=1.32-0.82 \ln (\rho), \\
B=3.0-0.76 \rho,
\end{gathered}
$$

where $v_{m}$ is fleeing velocity, $\mathrm{m} / \mathrm{s}$, generally taken as $1.669 \mathrm{~m} / \mathrm{s}$, the range of $\alpha$ is $0.25 \sim 0.44, \beta$ is $0.014 \sim 0.088$, and $\gamma$ is $0.15 \sim$ 0.26 .

Egress stream flow-rate depends on velocity and density, showed in (2):

$$
f(\rho)=v(\rho) \rho .
$$

Then the number of people evacuating through exit or passage is expressed as

$$
Q=f(\rho) w t=v(\rho) \rho w t
$$

where $w$ is the width of the evacuation exit or passage, $m$ and $t$ is evacuation time, $\mathrm{s}$.

Figure 3 shows the essential relationship of three parameters [24]. $v_{0}$ is free flow velocity, $\mathrm{m} / \mathrm{s}, f_{\max }$ is the maximum flow-rate value, person/(ms), and $\rho_{c}$ and $v_{c}$ are critical density and velocity, respectively, persons $/ \mathrm{m}^{2}, \mathrm{~m} / \mathrm{s}$. When crowd density is lower than the critical density, flow-rate increases as density increases, pedestrian flow in free flow state, but when crowd density is greater than the critical density, flowrate decreases as density increases, pedestrian flow in blocked state, where flow-rate and velocity decrease and density increases. $\rho_{s}$ is the safe density; in this situation, crowd is gathering but slowly flowing, and $\rho_{\max }$ is the maximum

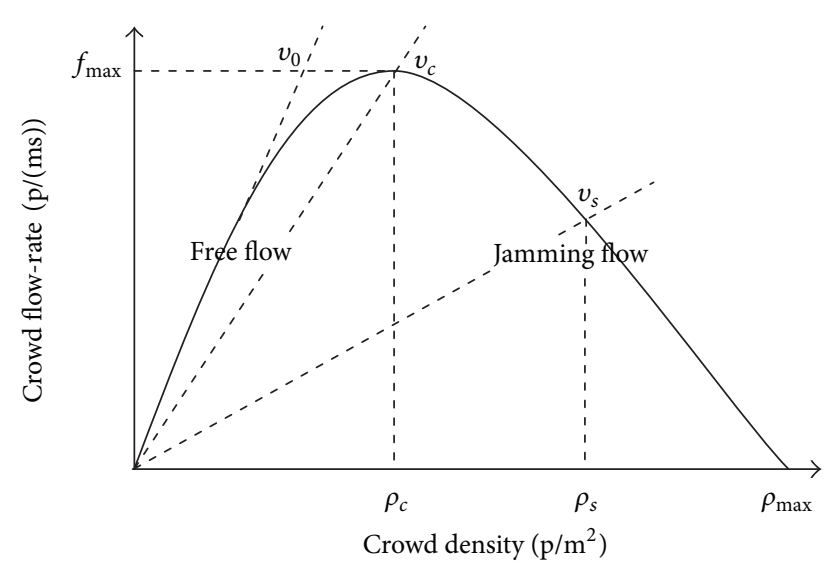

FIGURE 3: The essential relationship of crowd flow-rate, velocity and density.

density; flow-rate and velocity all equal zero, in a completely jammed situation [26].

The Green Guide [26] defines the limit of 4 persons $/ \mathrm{m}^{2}$ as a safe density for gathering crowd, that is, $\rho_{s}=4$ persons $/ \mathrm{m}^{2}$, and proposes $\rho_{\max }=7.4$ persons $/ \mathrm{m}^{2}$. Under extreme conditions, density of 15 persons $/ \mathrm{m}^{2}$ has been observed. According to the Chinese physical characteristic, we choose $\rho_{s}=3.57$ persons $/ \mathrm{m}^{2}$ as a safe density for a moving crowd and $\rho_{\max }=8$ persons $/ \mathrm{m}^{2}$ as a maximum density [27] in the jammed situation.

\section{Calculation Principle}

Streams of pedestrians evacuating towards a certain direction and the whole evacuation path inevitably encounter changed building space, such as path nodes, where streams merged into one, narrowed egresses, stairs, doors, steps, and so forth; these bottlenecks possibly become stranded zones due to clogging. Figure 4 shows a sketch of crowd flow. Assuming all leaving crowd will flow through the bottleneck into the next space, we define people who continue to flow in the zone as inflow crowd and out of the zone as outflow crowd; if jamming happens, crowd staying the zone as stranded crowd. Obviously, the balance principle of import and export applied and the number of stranded crowd should be the difference between numbers of inflow and outflow.

3.1. The Number of Inflow Crowd. Assuming several pedestrians' streams from internal passages merge into the bottleneck and then walk towards the next egress, the number of inflow crowd can be

$$
Q_{i}=\sum_{i=1}^{k} \int_{0}^{t} v_{i}(t) w_{i} \rho_{i}(t) d t
$$

where $Q_{i}$ is the number of inflow crowd from branch entrances; $v_{i}(t)$ and $\rho_{i}(t)$ are outflow velocity and density of branch entrances No. $i$ at time $t, \mathrm{~m} / \mathrm{s}$ and persons $/ \mathrm{m}^{2} ; w_{i}$ is the width of entrances No. $i, \mathrm{~m} ; k$ is the number of branch entrances; $t$ is the evacuation time, $s$. 


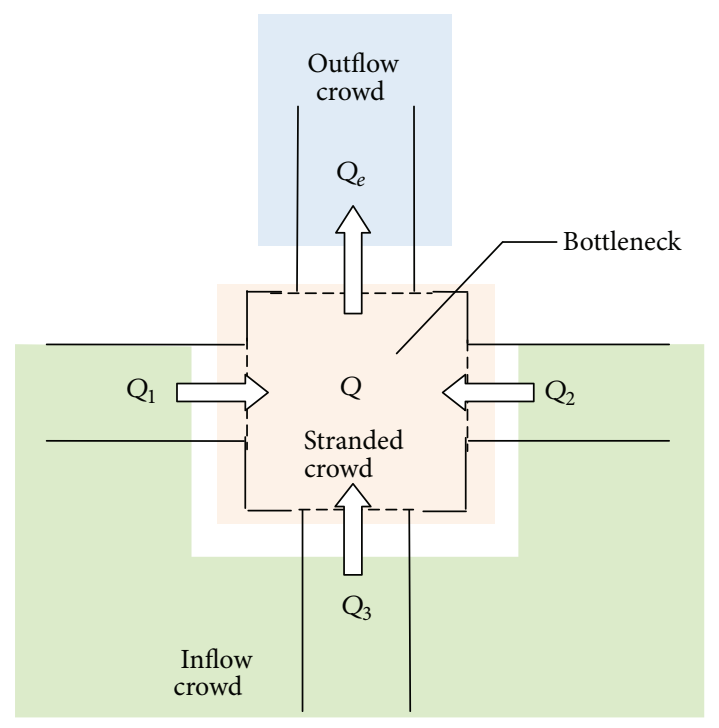

FIGURE 4: Sketch of crowd flow.

3.2. The Number of Outflow Crowd. During the time $t$, the evacuation crowd number of flowout of the bottleneck is

$$
Q_{e}=\sum_{i=1}^{k} \int_{0}^{t_{0}} v_{i}(t) w_{i} \rho_{i}(t) d t+\int_{t_{0}}^{t} v(t) w \rho(t) d t
$$

where $Q_{e}$ is the number of outflow crowd; $t_{0}$ is the time that the first person reaches the bottleneck exit, $s ; v(t)$ is the outflow velocity of the exit at time $t, \mathrm{~m} / \mathrm{s} ; w$ is the width of total exit, $\mathrm{m} ; \rho(t)$ is the density of bottleneck zone in front of the exit at time $t$, persons $/ \mathrm{m}^{2}$.

3.3. The Number of Stranded Crowd. Till the evacuation ends, the number of stranded crowds in the bottleneck zone $Q$ is

$$
\begin{aligned}
Q= & Q_{i}-Q_{e}=\sum_{i=1}^{k} \int_{0}^{t} v_{i}(t) w_{i} \rho_{i}(t) d t \\
& -\left(\sum_{i=1}^{k} \int_{0}^{t_{0}} v_{i}(t) w_{i} \rho_{i}(t) d t+\int_{t_{0}}^{t} v(t) w \rho(t) d t\right) \\
= & \sum_{i=1}^{k} \int_{t_{0}}^{t} v_{i}(t) w_{i} \rho_{i}(t) d t-\int_{t_{0}}^{t} v(t) w \rho(t) d t
\end{aligned}
$$

3.4. The Total Evacuation Time. When crowd streams all flow out of the exit to the next space, the evacuation ends. The time is

$$
t_{e}=t_{0}+\frac{\left(Q_{z}-\sum_{i=1}^{k} \int_{0}^{t_{0}} v_{i}(t) w_{i} \rho_{i}(t) d t\right)}{v^{\prime} f^{\prime} w}
$$

where $Q_{z}$ is the number of total evacuation people; $v^{\prime}, f^{\prime}$ are the outflow velocity and flow-rate of the exit at free flow, $\mathrm{m} / \mathrm{s}$, person/(ms).
The model is supposed that, when the evacuation velocity of the exit is equal to zero, no one is moving, and the exit is absolutely blocked, crowd density in the bottleneck is very high and arch-like clogging emerges, which must be prevented. This model also can calculate the smallest safe egress width based on the safe density and can calculate total evacuation time.

\section{Application Example}

In some stands of Tianjin Olympic Center Stadium as an example, evacuation routes include three longitudinal passages, one transverse passage, the hall in front of the egress, and the egress. The hall in front of the egress is a typical building bottleneck and becomes our main study field. The passage exit structure is shown in Figure 5.

4.1. Parameters Selection. Assuming the discussed stands have a seating capacity of 1400 ; that is, $Q_{z}=1400$; all persons are evenly distributed in the stands. Three longitudinal passages have the same width $w_{l}, w_{l}=1.1 \mathrm{~m}$, enough to allow up to two spectators to walk simultaneously. Transverse passage width $w_{t}$ is $w_{t}=1.6 \mathrm{~m}$, stranded-crowd zone width $w$ is $w=3.3 \mathrm{~m}$ and egress width $w_{e}$, is a varying value.

The distance from one longitudinal passage entrance to the stranded-crowd zone is $l_{t}, l_{t}=3 \mathrm{~m}$. The length from the egress to the edge of transverse passage is $l_{l}, l_{l}=1.4 \mathrm{~m}$. The area of stranded-crowd zone is $A, A=\left(w \times\left(l_{l}+w_{t}\right)\right) \mathrm{m}^{2}$.

According to the Design Code for Sports Building (JCJ312003) of China [28], assuming one stream of crowd flow is 40 persons/min and one crowd stream breadth is $0.55 \mathrm{~m}$, then flow-rate is

$$
f=\frac{40}{(60 \times 0.55)}=1.2 \operatorname{person} /(\mathrm{ms}) .
$$

In this paper, we ignore the time of spectators leaving seats to longitudinal passages and only consider the process of spectators beginning to flow into the transverse passage from stands entrances.

4.2. The Number of Stranded Crowd. At the very beginning of the evacuation, because the number of people flowing into the bottleneck is small, they can freely flow out of the egress. As people numbers increase, stranded crowd appears.

The number of stranded crowd can be calculated as follows:

(1) $t \leq t_{0}\left(t_{0}=L / v_{0}\right)$

$$
\begin{aligned}
Q(t) & =\sum_{i=1}^{k} \int_{0}^{t} v_{i}(t) w_{i} \rho_{i}(t) d t \\
& =\sum_{i=1}^{k} \int_{0}^{t} f_{i}(t) w_{i} d t=k f w_{l} t
\end{aligned}
$$

where $Q(t)$ is the initial number of stranded crowd in the bottleneck during the time $t \leq t_{0} ; v_{0}$ is the desired velocity 


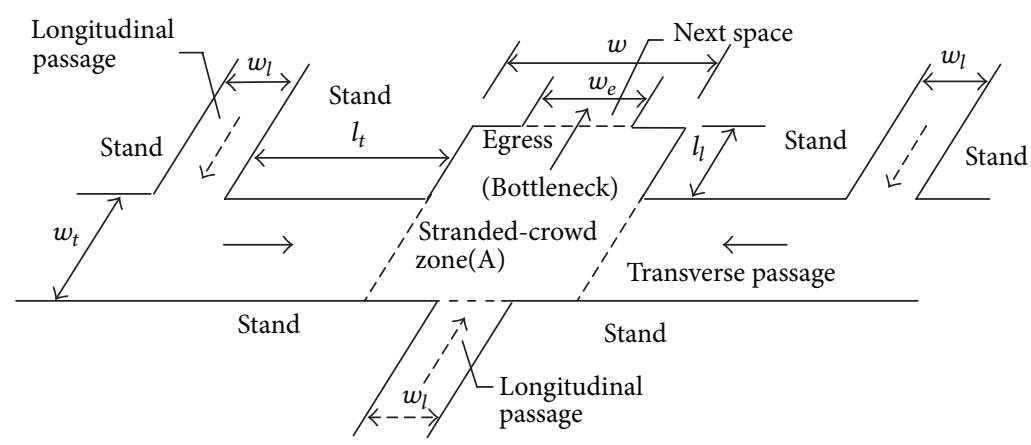

Figure 5: The plan of stands exit of Tianjin Olympic Center Stadium.

during the evacuation, $v_{0}=1.5 \mathrm{~m} / \mathrm{s} ; L$ is the nearest distance from stands entrances to the bottleneck egress, $L=l_{l}+w_{t}$; $f$ is inflow rate, $f=1.21$ person $/(\mathrm{ms})$ and $k=3$;

(2) $t_{0}<t \leq t_{1}$

$$
\begin{aligned}
Q_{e}(t) & =\int_{t_{0}}^{t} v(t) w \rho(t) d t=v(t) \rho(t) w_{e} t, \\
\rho(t) & =\frac{Q(t)}{A}=\frac{Q(t)}{\left(w \times\left(l_{l}+w_{t}\right)\right)} .
\end{aligned}
$$

Because this model is based on crowd dynamics, the relationship between crowd density and crowd velocity of the egress of the bottleneck as shown in (1) is used, which is more suitable for the high-density crowd of buildings. We adopt the parameters from HMSO [24]; that is, $\alpha=0.32, \beta=0.021$, and $\gamma=0.25$, and substituting (1) into (10), then

$$
\begin{aligned}
& Q_{e}(t)= v(t) \rho(t) w_{e} t \\
&=(1.669(0.32(1.32-0.83 \ln \rho(t)) \\
&+0.021(3-0.76 \rho(t))+0.25)) \rho(t) w_{e} t \\
&=\left(1.23 \rho(t)-0.44 \rho(t) \ln \rho(t)-0.03 \rho(t)^{2}\right) w_{e} t, \\
& Q(t)=\sum_{i=1}^{k} \int_{0}^{t} v_{i}(t) w_{i} \rho_{i}(t) d t \\
&-\int_{t_{0}}^{t} v(t) w \rho(t) d t \\
&= Q(t-1)+k w_{l} f \Delta t-Q_{e}(t-1) .
\end{aligned}
$$

At time $t_{1}$, the egress crowd velocity is equal to zero, which means no one can pass through the egress. $Q_{e}(t)$ is the number of outflow crowd during the time $t_{0}<t \leq t_{1} ; \Delta t$ is the time step, because $\rho(t)$ and $v(t)$ are variables of time, and $Q(t)$ is the dynamic value with time, and $Q(t-1), Q_{e}(t-1)$ are the number of stranded and outflow crowd at the prior time, the time $t-1$.

\section{Results and Analysis}

5.1. The Curves of the Number of Stranded Crowd and Outflow Crowd. From the above calculation, the curves of the number of stranded crowd and outflow crowd varying with time are

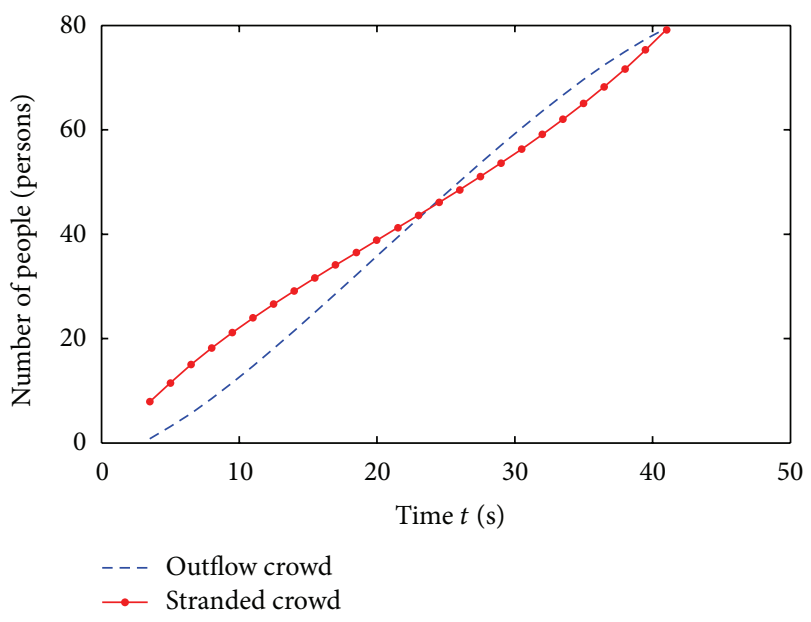

FIGURE 6: The curves of people number $\left(w_{e 1}=1.1 \mathrm{~m}\right)$.

obtained and compared with four different egress widths $\left(w_{e 1}=1.1 \mathrm{~m}, w_{e 2}=1.8 \mathrm{~m}, w_{e 3}=2.2 \mathrm{~m}\right.$, and $\left.w_{e 4}=3.3 \mathrm{~m}\right)$.

(1) $w_{e 1}=1.1 \mathrm{~m}$ : Figure 6 shows that the changes of two curves are not linear, and their gradients are similar. In the initial time, stranded-crowd number in the bottleneck is greater than outflow number, but when the time $t=$ $24.5 \mathrm{~s}$, they are equal; then outflow number is greater than stranded-crowd number. When $v^{\prime}$ (the velocity of outflow) approaches zero, stranded-crowd number increases quickly, and the density of the zone increases up to $\rho=8\left(\mathrm{p} / \mathrm{m}^{2}\right)$; at that time, $v^{\prime}=0, t=41 \mathrm{~s}$, and the egress is jammed.

(2) $w_{e 2}=1.8 \mathrm{~m}$ : Figure 7 shows that the gradients of two curves are apparently different. Outflow crowd number soon exceeds the stranded and becomes linear, but the number of stranded-crowd has been slow in growth until the time $t=$ $104 \mathrm{~s}$, and the rate of stranded-crowd number growth begins to have a sensible rise. When the time $t=135.5 \mathrm{~s}, v^{\prime}=0$, and $\rho=8.71\left(\mathrm{p} / \mathrm{m}^{2}\right)$, the egress is jammed.

(3) $w_{e 3}=2.2 \mathrm{~m}$ : Figure 8 shows the curve of outflow crowd number is simply linear and increasing rapidly, and the curve of the stranded number is linear initially. However, when the time $t=20 \mathrm{~s}$, the curve is horizontal, which means the stranded number is constant and the density of bottleneck $\rho=2.2\left(\mathrm{p} / \mathrm{m}^{2}\right)$. In that situation, we consider the crowd is safe, and evacuation crowd could freely flow out without any obstacle; $v^{\prime}=0.82 \mathrm{~m} / \mathrm{s}$. 


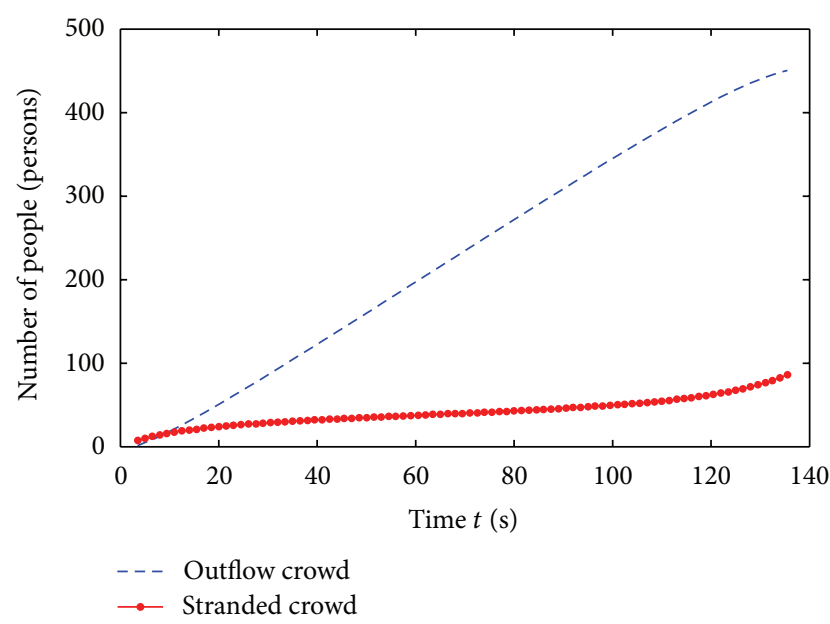

FIGURE 7: The curves of people number $\left(w_{e 2}=1.8 \mathrm{~m}\right)$.

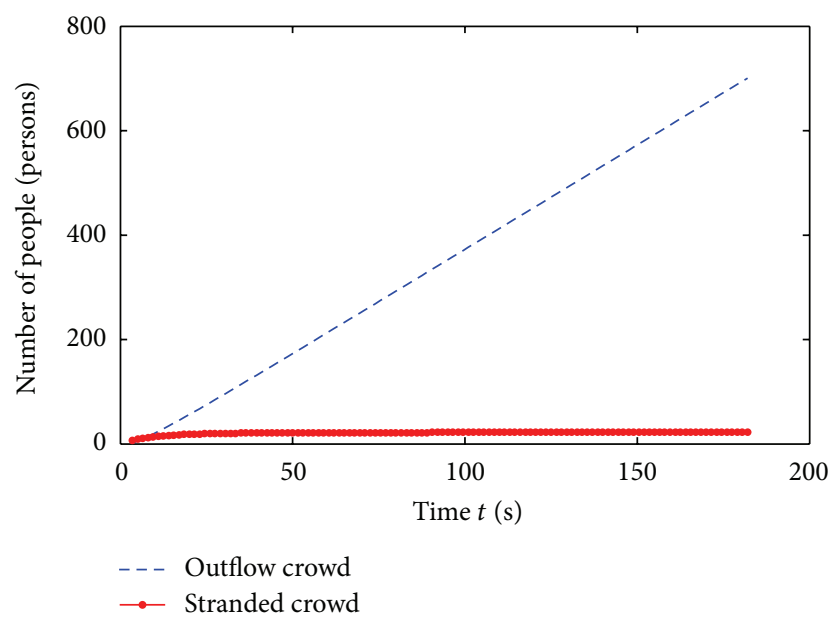

Figure 8: The curves of people number $\left(w_{e 3}=2.2 \mathrm{~m}\right)$.

(4) $w_{e 4}=3.3 \mathrm{~m}$ : The egress width in a stadium should be greater than or equal to the sum of the widths of served stand passages or egresses [28]; so we choose $w_{e 4}=w=3.3 \mathrm{~m}$ for calculation and that is equivalent to the egress completely opened. Figure 9 shows the calculation results are similar to the curves when the width $w_{e 3}=2.2 \mathrm{~m}$, except for when the density decreases, $\rho=1\left(\mathrm{p} / \mathrm{m}^{2}\right), v^{\prime}=1.2 \mathrm{~m} / \mathrm{s}$. All evacuation is not obstructed at all. In addition, the results are according to the regulation of the Design Codes for Sports Building (JCJ31-2003) of China [28], which further verifies this model's effectiveness.

5.2. The Relationship of Crowd Density and Egress Width in the Bottleneck. Comparing the density with the egress width from $1.8 \mathrm{~m}$ to $2.2 \mathrm{~m}$ in the bottleneck, we observed that it slips very fast (Table 1); so we consider there may be a critical width which is the threshold value of safe width. In order to solve this problem, the density with different egress widths is calculated, and the results are shown in Figure 10.

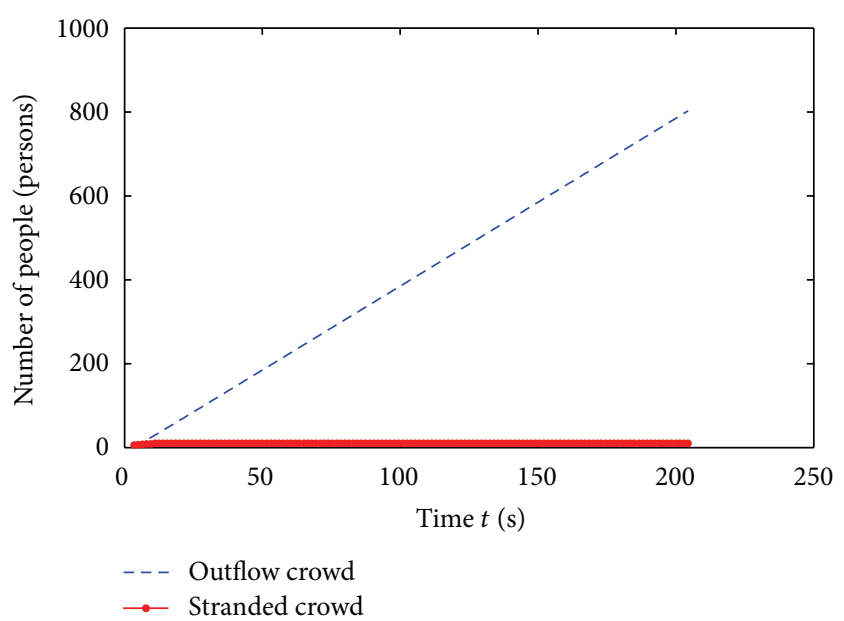

Figure 9: The curves of people number $\left(w_{e 4}=3.3 \mathrm{~m}\right)$.

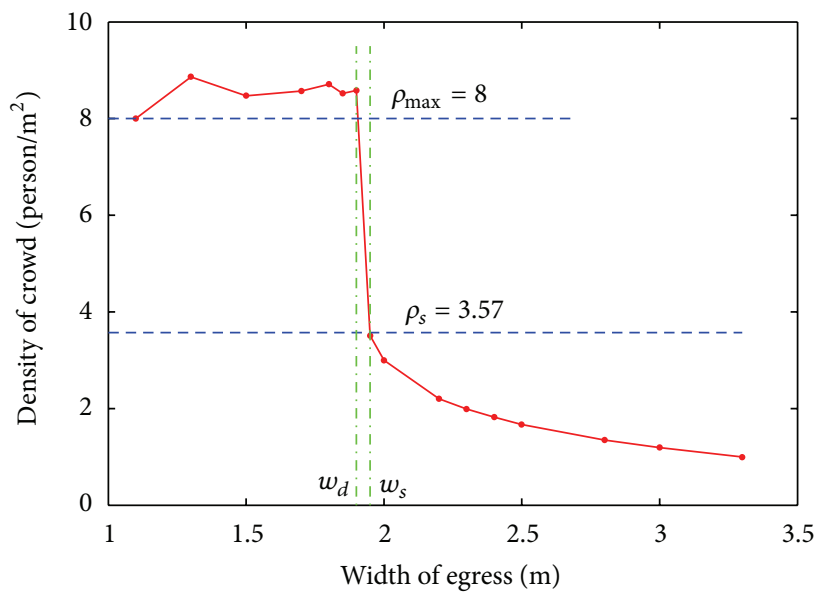

FIGURE 10: Relationship between crowd density and egress width.

From the above analysis, $\rho_{s}, \rho_{\max }$, the corresponding safe width $w_{s}$, and dangerous width $w_{d}$ are labeled, respectively, in Figure 10.

When $\rho \geq \rho_{\max }$ and $w_{d} \leq 1.9 \mathrm{~m}$, the density of the crowd is extremely high, and the physical movement of pedestrians is almost impossible. This situation is terribly dangerous, because while pedestrians are still standing, when crushing occurs, the high pressure within the crowd compresses the lungs of some individuals in the crowd, producing fatalities from asphyxiation [17]. So the width of egress must be bigger than $w_{d}$, and inspection of the bottleneck density is very significant.

When $\rho_{s} \leq \rho<\rho_{\max }, 1.95<w \leq 1.9 \mathrm{~m}$; although the width increases a little, the density decreases significantly, which seemingly small changes to the architecture of the surroundings can have such a large impact on the behavior of crowd, particularly when a crowd is panicked. After the density suddenly inclines up to $\rho_{s}=3.57$ persons $/ \mathrm{m}^{2}$, with the width increasing, density is smoothly decreasing; so the safe width, $w_{s}=1.95$, is the threshold width value, which does not lead to high density in theory. 
TABLE 1: Parameters with different width.

\begin{tabular}{lccc}
\hline $\begin{array}{l}\text { Egress width } \\
(\mathrm{m})\end{array}$ & $\begin{array}{c}\text { Jamming time } \\
(\mathrm{s})\end{array}$ & $\begin{array}{c}\text { Crowd density } \\
\left(\mathrm{p} / \mathrm{m}^{2}\right)\end{array}$ & $\begin{array}{c}\text { Velocity } \\
(\mathrm{m} / \mathrm{s})\end{array}$ \\
\hline 1.1 & 41 & 8 & 0 \\
1.8 & 136 & 8.71 & 0 \\
2.2 & - & 2.2 & 0.82 \\
3.3 & - & 1 & 1.2 \\
\hline
\end{tabular}

\section{Conclusion}

The people evacuation calculation model, based on the crowd dynamics when the exit jammed, is presented in this paper. The main characteristics of the evacuation streams, people's safety under emergency conditions, and comparison of the results using dynamics formula with different egress widths for the movement in a stadium example are all discussed.

Safe egress width is within a stone's throw of dangerous egress width, when a crowd is panicked. Small changes to the architecture of the surroundings can have large effects on the behavior of crowd.

This stranded-crowd model can calculate total evacuation time, which will be carried out in future work.

\section{References}

[1] Y. Liu, D. M. Liu, B. Norman et al., "Analysis of evacuation performance of merging points in stadiums based on crowd simulation," in Proceedings of the 12th Conference of the In-ternational Building Performance Simulation Association (IBPSA, BS'11), pp. 2651-2658, November 2011.

[2] X. Pan, C. S. Han, K. Dauber, and K. H. Law, "Human and social behavior in computational modeling and analysis of egress," Automation in Construction, vol. 15, no. 4, pp. 448-461, 2006.

[3] S. Chen, Y. Zheng, C. Cattani, and W. Wang, "Modeling of biological intelligence for SCM system optimization," Computational and Mathematical Methods in Medicine, vol. 2012, Article ID 769702, 10 pages, 2012.

[4] S. Wen, W. Zheng, J. Zhu, X. Li, and S. Chen, "Elman fuzzy adaptive control for obstacle avoidance of mobile robots using hybrid force/position incorporation," IEEE Transactions on Systems, Man and Cybernetics C, vol. 42, no. 4, pp. 603-608, 2012.

[5] K. J. Zhu and L. Z. Yang, "The effects of exit position and internal layout of classroom on evacuation efficiency," Acta Physica Sinica, vol. 59, no. 11, pp. 7701-7707, 2010.

[6] W. G. Song, Y. F. Yu, and T. Chen, "Influences of exit condition on pedestrian evacuation," Fire Safety Science, vol. 12, no. 2, pp. 100-105, 2003.

[7] D. Helbing and P. Molnar, "Social force model for pedestrian dynamics," Physical Review E, vol. 51, no. 5, pp. 4282-4288, 1995.

[8] M. Isobe, T. Adachi, and T. Nagatani, "Experiment and simulation of pedestrian counter flow," Journal of Fire Protection Engineering, vol. 4, no. 3, pp. 81-92, 1992.

[9] V. Papinigis, E. Geda, and K. Lukošius, "Design of people evacuation from rooms and buildings," Journal of Civil Engineering and Management, vol. 16, no. 1, pp. 131-139, 2010.

[10] S. Chen, W. Huang, C. Cattani, and G. Altieri, "Traffic dynamics on complex networks: a survey," Mathematical Problems in Engineering, vol. 2012, Article ID 732698, 23 pages, 2012.
[11] C. Cattani, R. Badea, S. Chen, and M. Crisan, "Biomedical signal processing and modeling complexity of living systems," Computational and Mathematical Methods in Medicine, vol. 2012, Article ID 298634, 2 pages, 2012.

[12] Q. S. Zhang, M. Liu, C. H. Wu, and G. Zhao, "A stranded-crowd model (SCM) for performance-based design of stadium egress," Building and Environment, vol. 42, no. 7, pp. 2630-2636, 2007.

[13] Q. S. Zhang, M. Liu, J. Liu, and G. Zhao, "Modification of evacuation time computational model for stadium crowd risk analysis," Process Safety and Environmental Protection, vol. 85, no. 6, pp. 541-548, 2007.

[14] Q. Liu, H. Yang, H. P. Lu, and S. Jing, "Study on the dispersal of people flow in the stadium," China Civil Engineering Journal, vol. 37, no. 10, pp. 92-98, 2004.

[15] S. Y. Chen, Y. H. Wang, and C. Cattani, "Key issues in modeling of complex 3D structures from video sequences," Mathematical Problems in Engineering, vol. 2012, Article ID 856523, 17 pages, 2012.

[16] D. Helbing, I. Farkas, and T. Vicsek, "Simulating dynamical features of escape panic," Nature, vol. 407, no. 6803, pp. 487490, 2000.

[17] R. S. C. Lee and R. L. Hughes, "Exploring trampling and crushing in a crowd," Journal of Transportation Engineering, vol. 131, no. 8, pp. 575-582, 2005.

[18] V. M. Predtechenskii and A. I. Milinski, Planning for Foot Traffic Flow in Buildings, Stroiizdat, Moscow, Russia, 1969.

[19] J. J. Fruin, Pedestrian Planning and Design, Metropolitan Association of Urban Designers and Environmental Planners, New York, NY, USA, 1971.

[20] K. Ando, H. Ota, and T. Oki, "Forecasting the flow of people," Railway Research Review, vol. 8, no. 45, pp. 8-14, 1988.

[21] J. L. Paul, "Effective width model for evacuation flow in buildings," Society of Fire Protection Engineers, vol. 4, no. 6, pp. 215-232, 1980.

[22] H. E. Nelson and H. A. Maclennan, Emergency Movement, NFPA, Quincy, Mass, USA, 1995.

[23] K. Smith and D. N. Petley, Environmental Hazards Assessing Risk and Reducing Disaster, Routledge, London, UK, 5th edition, 2008.

[24] J. A. Lu, Z. Fang, Z. M. Lu et al., "Mathematical model of evacuation speed for personnel in buildings," Engineering Journal of Wuhan University, vol. 35, no. 2, pp. 66-70, 2002.

[25] P. A. Thompson and E. W. Marchant, "Computer and fluid modelling of evacuation," Safety Science, vol. 18, no. 4, pp. 277289, 1995.

[26] Guide to Safety at Sports Grounds (Green Guide), Football Licensing Authority Department for Culture, Media and Sport (DCMS), TSO (The Stationery Office), 5th edition, 2008.

[27] J. Chen, P. J. Zhang, W. Yang, and Q. Li, "Personnel evacuation strategy for theater based on systematic dynamics model," Journal of Natural Disasters, vol. 14, no. 6, pp. 125-132, 2005.

[28] Design Code for Sports Building (JCJ31-2003) of China, The Industry Standard of the People's Republic of China, Beijing, China, 2003. 


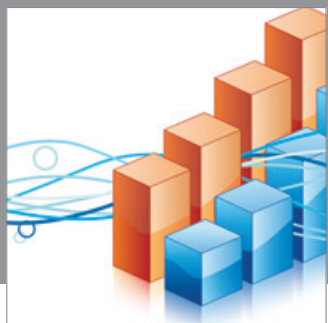

Advances in

Operations Research

mansans

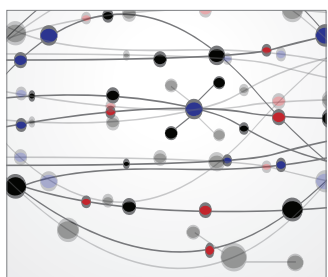

The Scientific World Journal
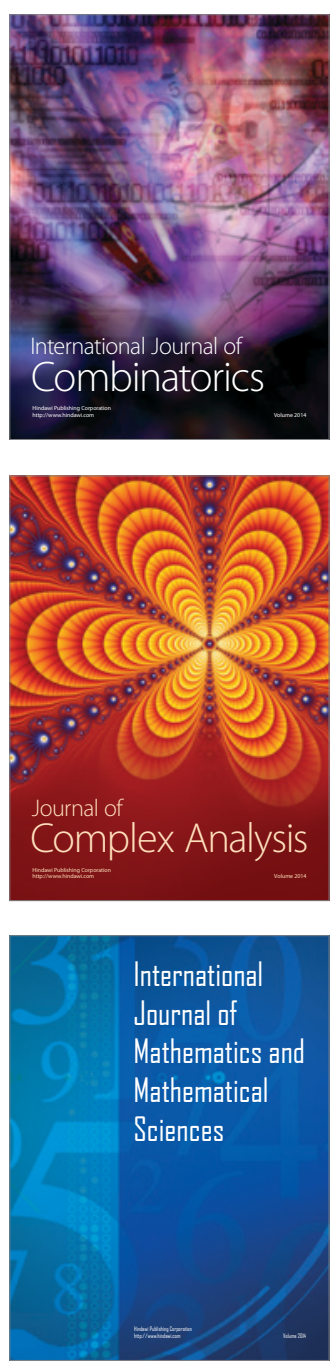
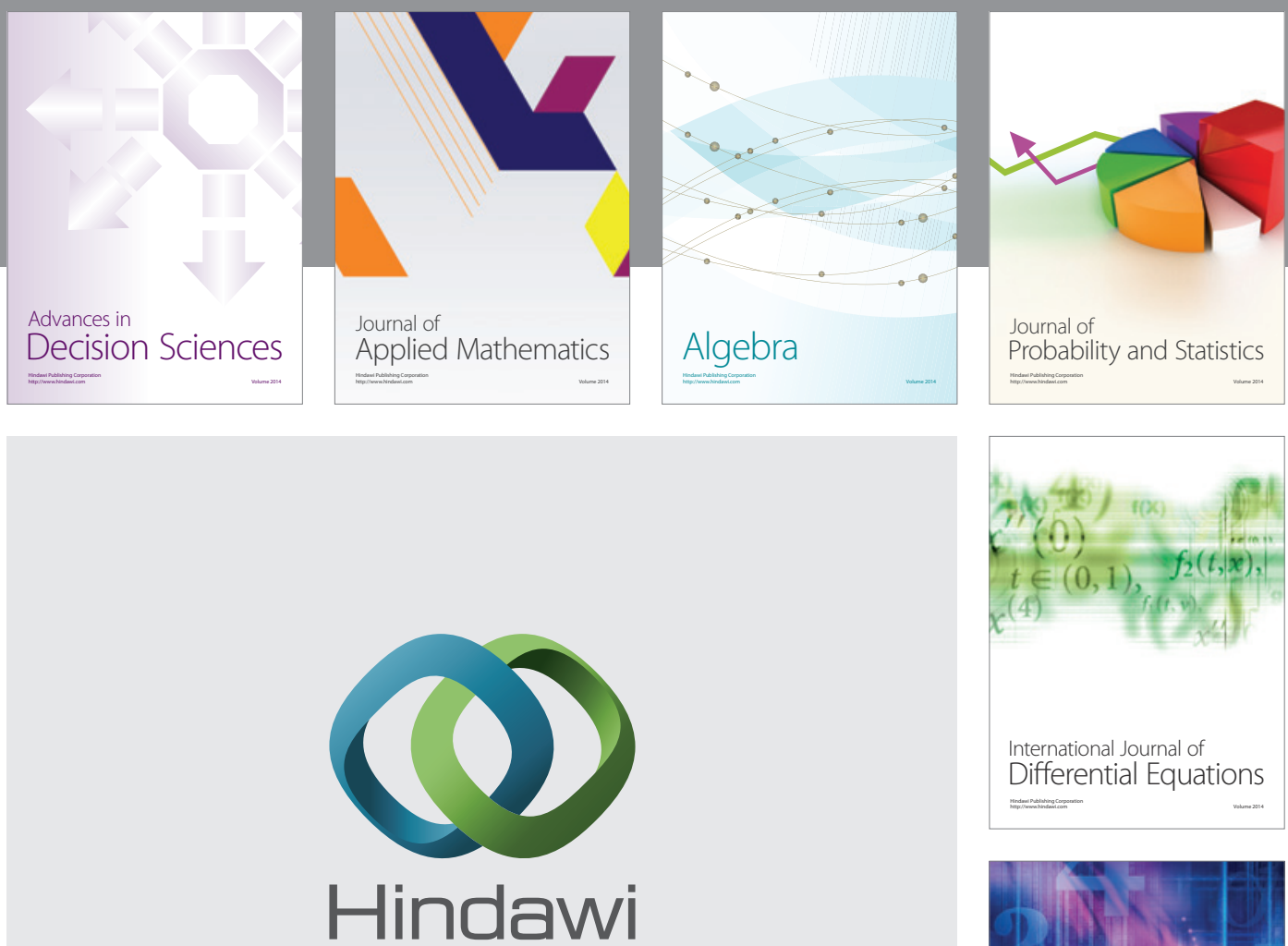

Submit your manuscripts at http://www.hindawi.com
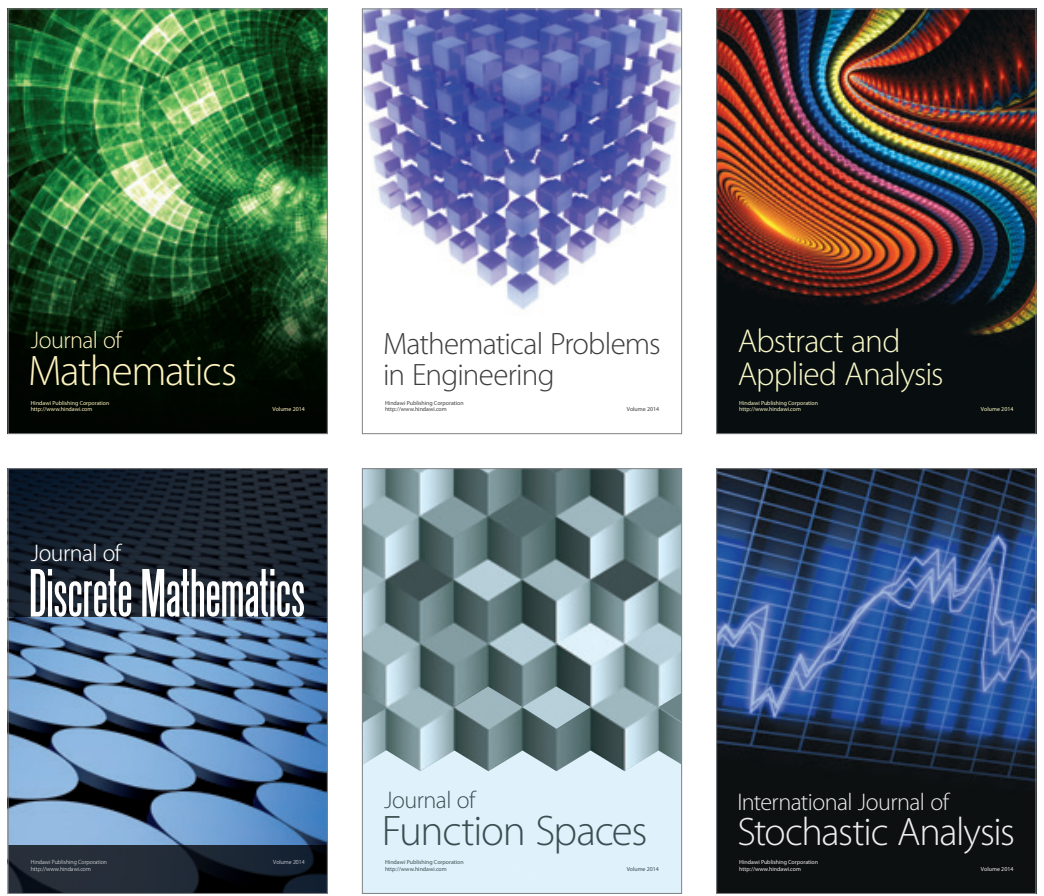

Journal of

Function Spaces

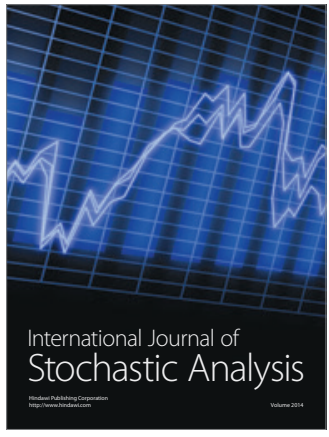

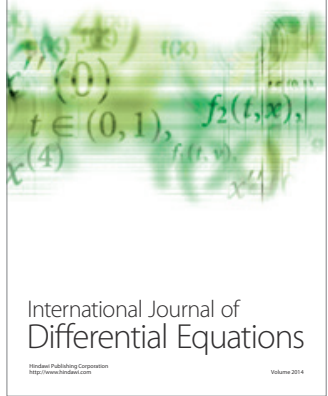
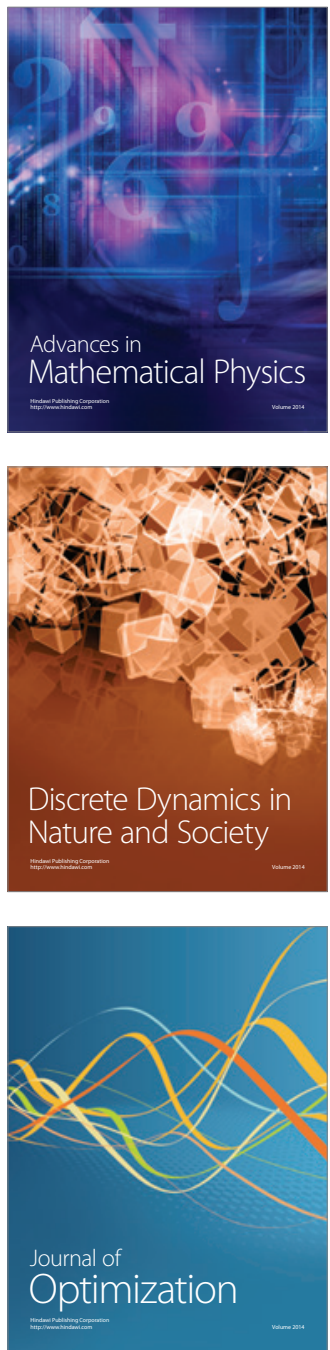